\title{
General Psychiatry Study of the relationship between self- stigma and subjective quality of life for individuals with chronic schizophrenia in the community
}

Yi Guo, Shumin Qu, Hongyun Qin

To cite: Guo Y, Qu S, Qin H. Study of the relationship between self-stigma and subjective quality of life for individuals with chronic schizophrenia in the community. General Psychiatry 2018;31:e100037. doi:10.1136/ gpsych-2018-100037

Received 19 November 2018 Accepted 19 November 2018

\section{ABSTRACT}

Background Studies conducted outside of China have found that stigma can predict low quality of life, and research in China has shown that stigma has an impact on the quality of life of convalescent patients with schizophrenia. Nevertheless, there is no indepth research on the impact of stigma on the quality of life of patients.

Aims To research the correlation of stigma and the subjective quality of life of persons with chronic schizophrenia in the community.

Methods We adopted a stratified sampling method. General questionnaire, quality of life scale and stigma scale were given to 602 persons with chronic schizophrenia in the community.

Results The mean (SD) value of the Subjective Quality of Life Scale total scores was 32.99 (13.85). The mean (SD) value of the total stigma scores was 43.50 (5.02). After correlation analysis and multivariate stepwise regression analysis, it was shown that the total scores for self-stigma and each factor were positively correlated with subjective quality of life $(r=0.462, p<0.001)$, psychosocial factors $(r=0.517, p<0.001)$, and symptoms and adverse reaction factor scores ( $r=0.363, p<0.001)$, and the correlation coefficients were statistically significant

Conclusions The higher the stigma of persons with schizophrenia in the community, the lower the subjective quality of life is. This suggests that reduction of self-stigma should be considered in the improvement of the quality of life of persons with schizophrenia in the community.

\section{BACKGROUND}

Psychiatric stigma ${ }^{1}$ is the stigma against psychiatric patients and the discrimination and rejection of the general public towards them. Stigma $^{23}$ can be divided into self-stigma and public stigma. The former refers to the stigma that hinders persons from talking about their own experiences and from seeking help, in addition to the worries and avoidance towards being discriminated against. The latter refers to the personal experience of patients being discriminated and treated unfairly. Selfstigma limits their own social circle, and it also constantly depreciates themselves, resulting in adverse consequences such as avoidance of social situations and suicide in the end. ${ }^{4}$ Studies from numerous fields, including clinical medicine, sociology and psychology, have shown that the impaired social functioning and mental disability of patients with chronic schizophrenia severely influence their quality of life. ${ }^{5}$ Studies outside of China have found that stigma is a predictor of a low quality of life. ${ }^{6-7}$ A study conducted in China in $2015^{8}$ showed that stigma has an impact on the quality of life of those with schizophrenia in the convalescent period. Nevertheless, there is no extended research on stigma and its impact on the quality of life of patients. Therefore, this study aims to investigate the relationship of stigma and quality of life in stay-at-home patients with schizophrenia in the Pudong New Area of Shanghai.

\section{METHODS}

Participants

A stratified sampling method was used. There were altogether 30 neighbourhoods which had community rehabilitation institution subordinated to the Pudong New Area mental disease prevention and treatment management. Each neighbourhood was randomly numbered with a natural number according to the total number of patients that was divided by 20 , resulting in the multiple of the sampling probability. For instance, there were 1056 community patients with schizophrenia in a neighbourhood and the sampling probability was 52 . The first subject of sampling was number 52 and the second one was number 104. If the participant did not meet the criteria for enrolment or refused to follow up, the next person in sequence would become the subject. The sampling continued until 24 patients were selected. In accordance with practice, households' separation, refusal to 


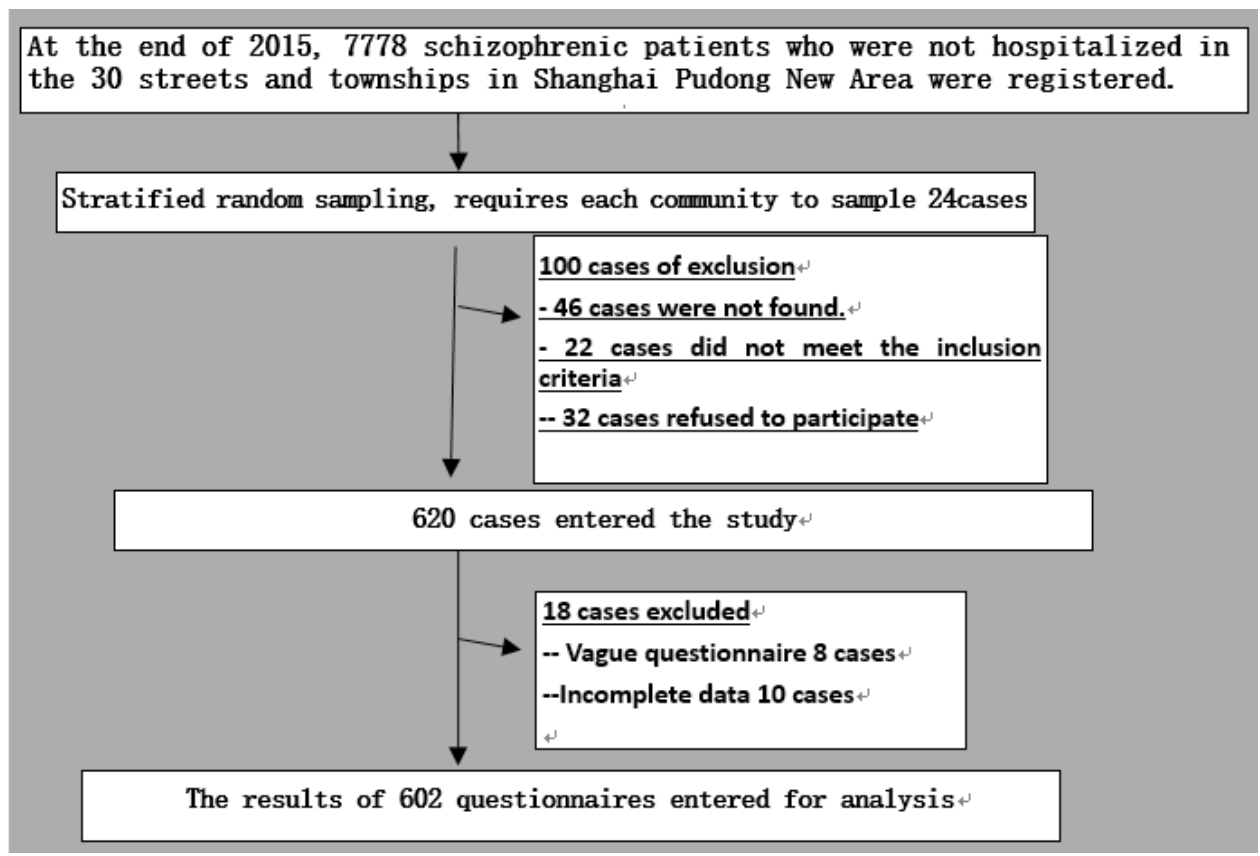

Figure 1 Demographic percentage figure.

visit and the number of investigations that could not be completed increased by $20 \%$.

The following were the inclusion criteria: (1) meeting the International Statistic Classification of Disease and Related Health Problems, 10th Revision, diagnostic criteria for schizophrenia; (2) aged between 18 and 65; (3) in community rehabilitation, have not been hospitalised in the past 3 years and in stable condition; and (4) Positive and Negative Syndrome Scale score less than 60. The following were the exclusion criteria: (1) currently having a major somatic disease; (2) diagnosed with intellectual disabilities or verbal communication disorders and failed to complete examination and evaluation; (3) with a high risk of suicide; (4) comorbidity with other severe mental disorders; and (5) patients who had never been treated in Shanghai medical institutions and therefore were not included in community management (figure 1).

\section{Methods}

\section{General information questionnaire}

A self-compiled general information questionnaire including general demographic information and disease information was used. The information was collected by community mental health specialists in consultation with the patients.

\section{Schizophrenia Quality of Life Scale}

The Schizophrenia Quality of Life Scale is a self-rating scale compiled by British psychiatrists Greg Wilkinson and Diane Wild and colleagues, and translated and revised by Luo Hong and colleagues ${ }^{9}$ from Zhejiang University. The test-retest reliability of the Chinese version was 0.87 and the internal consistency (alpha) coefficient was 0.700.92 , which was significantly correlated with he MOS item short form health survey (SF-36) and Symptom Checklist
90 (SCL-90). The questionnaire is a 5-point Likert scale with three subscales, namely psychosocial, motivation/ energy and symptoms/side effects. The final standard score is $0-100$; the lower the score, the better the subjective quality of life.

\section{Stigma Scale for Mental IIIness}

The Stigma Scale for Mental Illness was compiled by Qingzhi and colleagues ${ }^{10}$ from the mental health centre affiliated to Shanghai Jiao Tong University. The perceived level of discrimination was measured based on the feelings and experience of patients. A 4-point Likert scale was adopted, which included 3 factors and 32 items, and 8 of them were reversed items. The lower the score, the lower the self-stigma. After reliability analysis, the internal consistency coefficient of the scale was 0.90 , and the internal alpha coefficient of the three factors was between 0.68 and 0.85 . The correlation coefficient between the factors was between 0.63 and 0.75 .

\section{Statistical analysis}

All data were processed using SPSS V.17.0 software. A database was established. The data were entered by a specially assigned person and analysed by a specialist who had not participated in the investigation. Quantitative data were expressed in terms of means and SD. Qualitative data were expressed in n (\%). Pearson's correlation and stepwise multiple regression analysis were used to analyse the relationship between the scores of the two scales.

\section{RESULTS}

General demographic information

A total of 620 patients with chronic mental illness in the community were surveyed and 602 valid questionnaires 
were collected through strict quality control (97.10\%). Among them, $292(48.5 \%)$ cases were male and 310 $(51.5 \%)$ were female; $332(55.1 \%)$ were unmarried, 215 $(35.7 \%)$ were married, and 55 (9.2\%) were widowed, separated or divorced. The following were the living conditions of the participants: living alone 17 cases (2.8\%); unmarried and living with family 331 cases $(55.0 \%)$; married nuclear family 154 cases (25.6\%); and married stem family 100 cases $(16.6 \%)$. The following were the educational attainment of the participants: primary school $56(9.3 \%)$ cases, junior middle school 323 (53.7\%), senior high school 179 $(29.7 \%)$, and collage or above $44(7.3 \%)$. Of the participants, $52(8.6 \%)$ were employed (full time and part-time), $467(77.8 \%)$ were unemployed and $83(13.8 \%)$ were retired (see details in table 1 and figure 2).

The current average age of the patients was 44.56 (10.63) years old, mostly $31-45$ years old (268 cases, $44.5 \%$ ) and 46-60 years old (223 cases $37.0 \%$ ), and there were 56 cases $(9.3 \%)$ who were 30 years old or below and 55 cases $(9.1 \%)$ who were 61 years old or above. The age of onset was 25.58 (9.05) years old, mostly $18-30$ years old (345 cases, $57.3 \%$ ), 102 cases were under 18 years old $(16.9 \%)$ and 155 cases were $31-50$ years old (25.7\%).figure 3

\section{Course of illness, hospitalisation and medication}

The average course of illness was 18.95 (9.32) years, 360 $(59.8 \%)$ patients with 16 years or more, $116(19.3 \%)$ patients with 11-15 years, 99 (16.4\%) patients with 6-10 years, and $27(4.5 \%)$ patients with less than 5 years. There were 249 stay-at-home patients $(41.4 \%)$ who had never been hospitalised since the diagnosis, and the average number of

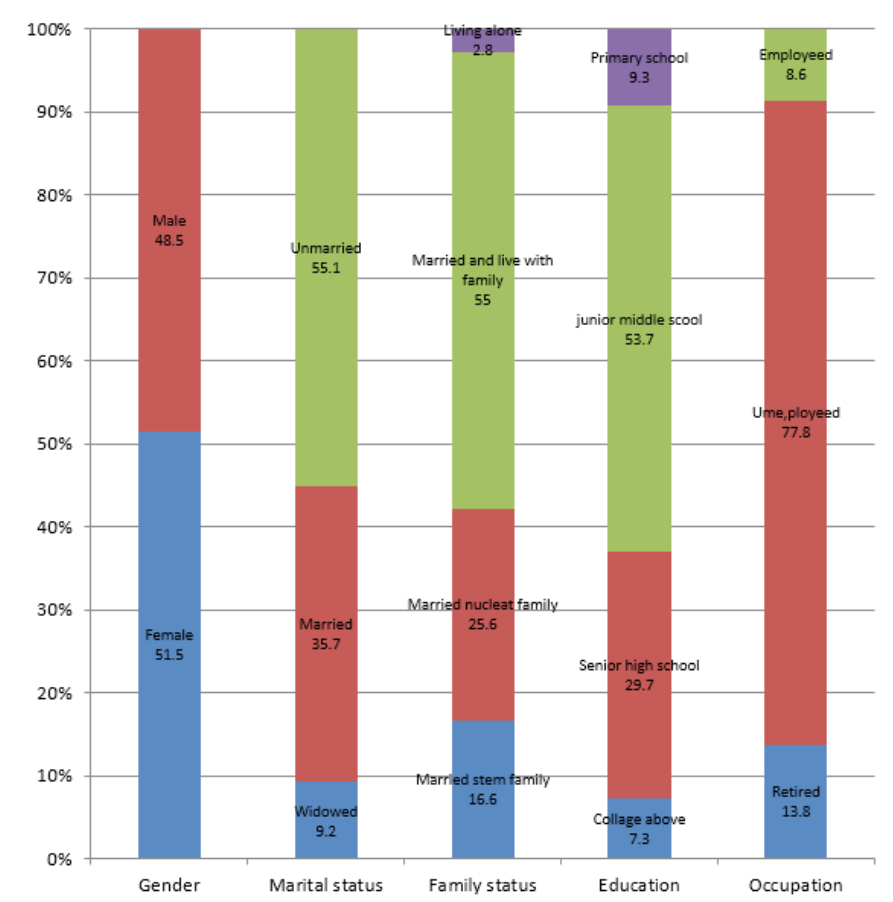

Figure 2 Demographic percentage figure.

hospitalisations for the rest of the patients was 2.32 (1.61) times; $323(53.7 \%)$ patients were hospitalised one to three times and 30 patients $(5.0 \%)$ more than four times. There were 579 cases $(96.2 \%)$ that received drug therapy, and currently 22 cases $(3.7 \%)$ refused medication (see table 2 and figure 3 for details).

Table 1 Stepwise multivariate regression analysis of the influencing factors of subjective quality of life in stay-at-home patients with schizophrenia

\begin{tabular}{|c|c|c|c|c|c|c|}
\hline \multirow[b]{2}{*}{ Content } & \multirow[b]{2}{*}{$\mathbf{n}$} & \multirow[b]{2}{*}{ Percentage } & \multicolumn{2}{|c|}{$\begin{array}{l}\text { Subjective quality of life total } \\
\text { score }\end{array}$} & \multicolumn{2}{|c|}{ Stigma total score } \\
\hline & & & Mean (SD) & $F / t$ (p values) & Mean (SD) & $F$ (p values) \\
\hline \multicolumn{7}{|l|}{ Gender } \\
\hline Male & 292 & 48.5 & $32.37(13.11)$ & $1.152(0.282)$ & $42.19(14.28)$ & $4.407\left(0.036^{*}\right)$ \\
\hline Female & 310 & 51.5 & $33.58(14.51)$ & & $44.76(15.58)$ & \\
\hline \multicolumn{7}{|l|}{ Marital status } \\
\hline Unmarried & 332 & 55.1 & $33.20(13.00)$ & $3.271\left(0.039^{*}\right)$ & $44.05(13.80)$ & $3.393\left(0.034^{*}\right)$ \\
\hline Married & 215 & 35.7 & $33.81(14.63)$ & & $43.91(16.20)$ & \\
\hline Widowed, separate or divorced & 55 & 9.2 & $28.55(15.07)$ & & $16.54(2.23)$ & \\
\hline \multicolumn{7}{|l|}{ Employment } \\
\hline Employed & 52 & 8.6 & $39.22(14.02)$ & $10.490\left(<0.001^{\star \star}\right)$ & $44.29(16.83)$ & $0.668(0.526)$ \\
\hline Unemployed & 467 & 77.6 & 30.27 (13.09) & & $41.38(15.47)$ & \\
\hline Retired & 83 & 13.8 & $32.19(13.63)$ & & $43.61(14.62)$ & \\
\hline \multicolumn{7}{|l|}{ Number of hospitalisations } \\
\hline Never hospitalised & 222 & 36.88 & $33.53(13.13)$ & $2.463(0.086)$ & $44.81(14.53)$ & $5.711\left(0.003^{\star}\right)$ \\
\hline Hospitalised below three times & 324 & 53.82 & $32.06(14.34)$ & & $41.81(15.48)$ & \\
\hline Hospitalised above three times & 56 & 9.30 & $32.99(13.85)$ & & $48.21(12.63)$ & \\
\hline Total & 602 & 100 & $32.99(13.85)$ & & $43.51(15.01)$ & \\
\hline
\end{tabular}

${ }^{*} \mathrm{P}<0.05,{ }^{* *} \mathrm{p}<0.01$. 


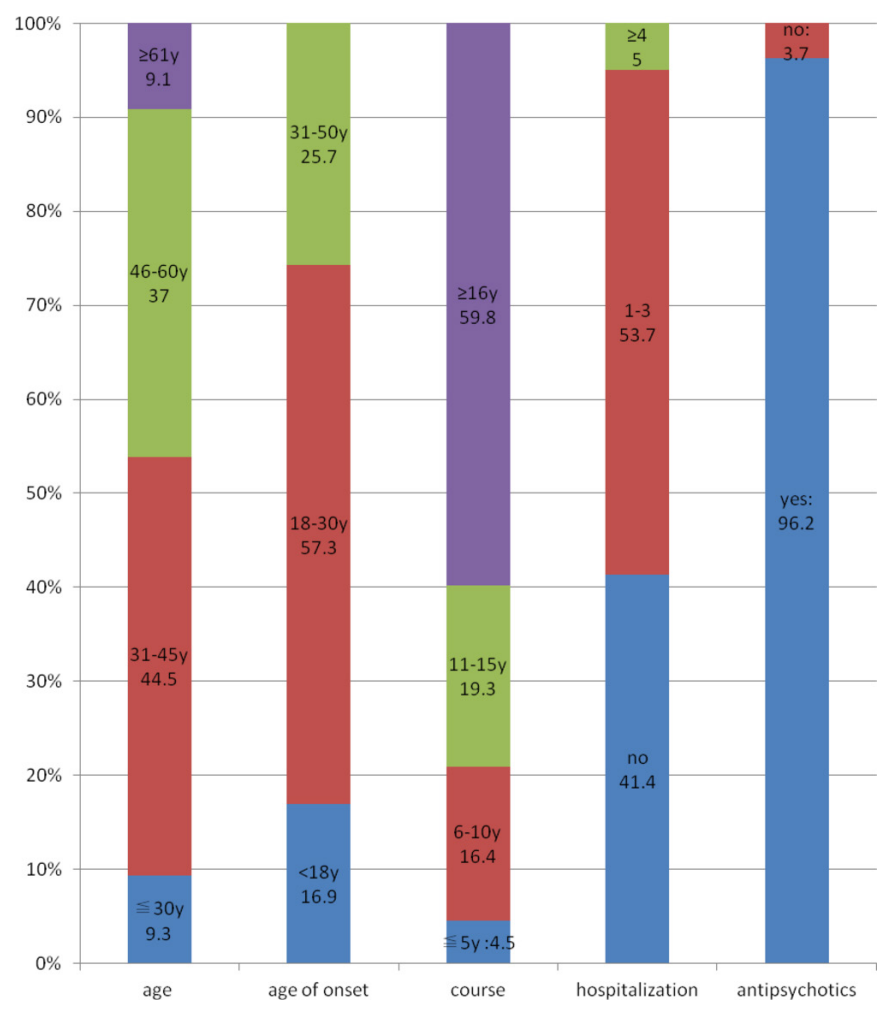

and side effect factors (the correlation coefficients were $0.360,0.333,0.352$ and $0.296 ; p<0.001)$, respectively, and the differences were statistically significant. Nevertheless, the correlations with the energy/motivation factors of the subjective quality of life were not statistically significant (see table 2 for details).

Regression analysis of the subjective quality of life and stigma scores in stay-at-home patients with schizophrenia In univariate analysis, it was found that marital status, family status, occupation and course of illness had significant effects on subjective quality of life, while gender, number of hospitalisations and marital status had significant effects on self-stigma (see table 1). Therefore, after controlling for factors such as gender, educational attainment, occupation, marital status, family status, number of hospitalisations, whether medicated or not, age of onset and course of illness, and for subjective quality of life and self-stigma as continuous variables, further regression analysis found that self-stigma and quality of life were positively correlated. In short, the higher the self-stigma and the higher the subjective quality of life, the lower the quality of life actually was (see table 3 and figure 3 for details).

Figure 3 Schizophrenia characteristics distribution figure.

\begin{tabular}{|c|c|c|c|c|c|}
\hline Items & & Stigma total score & Social factor & Functioning factor & Treatment factor \\
\hline $\begin{array}{l}\text { Schizophrenia Quality of Life Scale } \\
\text { total score }\end{array}$ & $r(p)$ & $0.462\left(<0.001^{\star \star}\right)$ & $0.457\left(<0.001^{* \star}\right)$ & $0.419\left(<0.001^{\star \star}\right)$ & $0.351\left(<0.001^{* *}\right)$ \\
\hline Psychosocial & $r(p)$ & $0.517\left(<0.001^{\star \star}\right)$ & $0.519\left(<0.001^{\star *}\right)$ & $0.470\left(<0.001^{* \star}\right)$ & $0.379\left(<0.001^{\star \star}\right)$ \\
\hline Motivation/energy & $r(p)$ & $-0.015(0.721)$ & $0.004(0.929)$ & $-0.58(0.156)$ & $-0.01(0.972)$ \\
\hline Symptoms/side effects & $r(p)$ & $0.360\left(<0.001^{\star \star}\right)$ & $0.333\left(<0.001^{\star \star}\right)$ & $0.352\left(<0.001^{\star \star}\right)$ & $0.296\left(<0.001^{\star \star}\right)$ \\
\hline
\end{tabular}

${ }^{*} p<0.05,{ }^{* *} p<0.01$.

Scores of the quality of life scale of community patients with chronic schizophrenia and Stigma Scale for Mental IIIness

The total score for the quality of life scale of community patients with chronic schizophrenia was 32.99 (13.85). The mean scores of the three factors were 32.47 (18.43) for psychosocial, 47.21 (11.96) for energy and motivation, and 21.53 (17.36) for symptoms and side effects. The total score for self-stigma was 43.50 (15.02), and the mean scores of the three factors were 10.80 (4.14) for functioning, 20.37 (7.57) for social intercourse and 12.32 (4.99) for treatment, respectively.

\section{Correlation of self-stigma and subjective quality of life in community patients with chronic schizophrenia}

The Pearson's correlation analysis showed that the total scores for self-stigma, social factors of self-stigma, functioning factors and treatment factors were positively correlated with the total scores of subjective quality of life (the correlation coefficients were 0.462, 0.457, 0.419 and $0.351 ; p<0.001$ ), psychosocial factors (the correlation coefficients were $0.517,0.519$ and $0.470 ; p<0.001$ ), and symptoms
Table 3 Stepwise multivariate regression analysis of the influencing factors of subjective quality of life in stay-athome patients with schizophrenia

\begin{tabular}{lrlc}
\hline Items & $\boldsymbol{B}$ & \multicolumn{1}{l}{$\boldsymbol{l}$} & P values \\
\hline Constant & 3.84 & 0.714 & 0.475 \\
\hline Gender & 0.279 & 0.275 & 0.783 \\
\hline Educational attainment & 0.440 & 0.632 & 0.528 \\
\hline Employment & 1.284 & 1.595 & 0.111 \\
\hline Marital status & -3.034 & -1931 & 0.054 \\
\hline Family status & 0.716 & 1.158 & 0.247 \\
\hline Number of hospitalisations & 0.244 & 0.805 & 0.421 \\
\hline Whether medicated or not & 0.973 & 0.360 & 0.79 \\
\hline Course of the illness & 0.123 & 1.987 & $0.047^{*}$ \\
\hline Age of onset & 0.147 & 2.294 & $0.002^{*}$ \\
\hline Stigma total score & 0.417 & 12.377 & $<0.001^{*}$ \\
\hline
\end{tabular}

${ }^{*} p<0.05,{ }^{* *} p<0.01$. 


\section{DISCUSSION}

\section{Main findings}

This study has shown that there is a positive correlation between subjective quality of life and self-stigma in community patients with chronic schizophrenia, and this result is consistent with that of Link and colleagues. ${ }^{11}$ It further explains that self-stigma can predict the subjective quality of life of patients.

The study also found that the higher the score of the social factor of self-stigma, the higher the total score of subjective quality of life, the score of psychosocial factors and symptom/side effects, indicating that the more patients avoid social contact and lock themselves out from others, the more difficult it is for them to integrate into the society, the more persistent their mental symptoms are and the lower the perceived quality of life. At the same time, the feeling of subjective quality of life conversely affects the perception of stigma of patients, leading to an increase in avoiding social situations and resulting in more serious withdrawal behaviours. The results are different from the proposal by scholars ${ }^{6}$ that a negative coping style cannot directly predict the quality of life of patients; however, they are consistent with the research results of Hong $\mathrm{Y}^{8}$ The low economic level in China might account for the differences. Due to the imperfection of the community rehabilitation model and the lack of comprehensive community rehabilitation resources, community patients with schizophrenia are prone to avoiding social situations and negative coping.

This study also found that the functioning and treatment factors of stigma were positively correlated with the total score, psychosocial and symptoms/side effects factors of subjective quality of life. The correlation suggests that increasing self-awareness in patients could result in lower subjective quality of life, thereby conversely aggravating stigma. Some scholars proposed ${ }^{812-14}$ that stigma affected treatment compliance, resulting in unstable symptoms, aggravating negative withdrawal reactions and deteriorating quality of life. By repeating this process, a vicious cycle is formed.

The results of this study found that patients with a longer course of illness had a lower subjective quality of life. However, the perceived stigma was not affected, which was consistent with the studies in China and abroad. ${ }^{1314}$ Nevertheless, this study showed that there was no statistical significance in the correlation between the perceived stigma and the motivation/energy factors of subjective quality of life, which deviated from the results of Chinese and foreign studies ${ }^{1315}$ that had indications of positive correlations. The deviation could be attributed to the subjects in current research were community-based chronic schizophrenia, and $79.1 \%$ of which had a course of more than 10 years. On one hand, the residuals had negative symptoms and were not sensitive to stigma and quality of life. On the other hand, $77.6 \%$ of patients have been unemployed for a long time, had no chance to integrate into the society and coped with life negatively, which led to low levels of life motivation and energy for an extended period of time. The patients appeared to be lack of interests and hobbies regardless of the perception of the self-stigma.

\section{Limitations}

There are some limitations to the current investigation. First, the patients had almost 10 years of illness, and most of them had no jobs, which may have affected the results. Second, the number of the scales we applied was small, which could not reflect the comprehensive feelings of self-stigma. Third, apathy symptoms, which may affect feelings of self-stigma, were not assessed.

\section{Implications}

Researchers are in need of interventions for self-stigma in order to improve the quality of life of patients with chronic schizophrenia in the community. Scholars in China have increasingly emphasised the impact of stigma on patients' quality of life. Furthermore, there are explorations on the reduction of stigma through social support to improve the quality of life of those patients with relatively good social functioning. There is also research on systematic methods and feasible rehabilitation means for patients with chronic degeneration in the community. This kind of research will continue to explore in practice and attempt to carry out targeted and feasible rehabilitation methods for these groups.

Contributors YG: in charge of the project and is the person of execution. SQ: project organiser, logistic support and data collation. $\mathrm{HQ}$ : quality control and data guidance.

Funding Sponsored by the Shanghai Municipal Health and Family Planning Commission in Pudong New Area (PW2015A-28) and the Shanghai Municipal Health and Family Planning Commission (201840372) .

Competing interests None declared.

Patient consent for publication Obtained.

Ethics approval This study was approved by the ethics committee of the Pudong New Area Mental Health Center in Shanghai (2015006).

Provenance and peer review Not commissioned; externally peer reviewed. Data sharing statement № additional data are available.

Open access This is an Open Access article distributed in accordance with the Creative Commons Attribution Non Commercial (CC BY-NC 4.0) license, which permits others to distribute, remix, adapt, build upon this work non-commercially, and license their derivative works on different terms, provided the original work is properly cited and the use is non-commercial. See: http://creativecommons.org/ licenses/by-nc/4.0

\section{REFERENCES}

1. Zhou Ying LY, Yajie L. Review of the investigations of stigma in schizophrenia. Guangdong Medical Journal 2011;32:2061-3.

2. Scambler G. Stigma and disease: changing paradigms. Lancet 1998;352:1054-5.

3. Jacoby A. Felt versus enacted stigma: a concept revisited. Evidence from a study of people with epilepsy in remission. Soc Sci Med 1994;38:269-74.

4. Lin CL, Kopelowicz A, Chan $\mathrm{CH}$, et al. A qualitative inquiry into the Taiwanese mentally ill persons' difficulties living in the community. Arch Psychiatr Nurs 2008;22:266-76.

5. Vogel DL, Wade NG, Hackler AH. Perceived public stigma and the willingness to seek counseling: The mediating roles of self-stigma and attitudes toward counseling. J Couns Psychol 2007;54:40-50. 
6. Ow CY, Lee BO. Relationships between perceived stigma, coping orientations, self-esteem, and quality of life in patients with schizophrenia. Asia Pac J Public Health 2015;27:1-10.

7. Leclerc E, Mansur RB, Brietzke E. Determinants of adherence to treatment in bipolar disorder: a comprehensive review. J Affect Disord 2013;149(1-3):247-52.

8. Hong Y, Lina W, Yuqiu Z, et al. The effect of stigma on the quality of life among convalescent schizophrenia patients: the mediating effect of social support and coping style. Chinese Nursing Management 2015;15:424-8.

9. Hong L, Nan L, Yiqiang W. Regability and Vaaday of the Schizophrenia Quality of Life Scale. Chinese Mental Health Journal 2003;17:172-4.

10. Qingzhi Z, Yanling H, Hong T. Development of Scale of Stigma in People with Mental IIIness. Chinese Mental Health Journal 2009;23:634--637.
11. Link BG, Struening EL, Neese-Todd S, et al. Stigma as a barrier to recovery: The consequences of stigma for the self-esteem of people with mental illnesses. Psychiatr Serv 2001;52:1621-6.

12. Ying Z, ShenMao P, Chunyang Z. Influence of stigma in Quality of Life of Patients with Mental Disorders. Chong Qing Medical Journal 2015;10:1349-51.

13. Sibitz I, Amering M, Unger A, et al. The impact of the social network, stigma and empowerment on the quality of life in patients with schizophrenia. Eur Psychiatry 2011;26:28-33.

14. Karidi MV, Stefanis CN, Theleritis C, et al. Perceived social stigma, self-concept, and self-stigmatization of patient with schizophrenia. Compr Psychiatry 2010;51:19-30.

15. Ho WW, Chiu MY, Lo WT, et al. Recovery components as determinants of the health-related quality of life among patients with schizophrenia: structural equation modelling analysis. Aust $N Z J$ Psychiatry 2010;44:71-84.

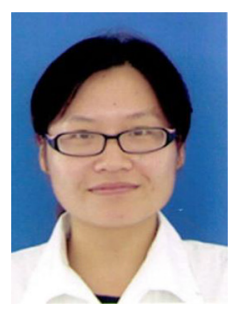

Yi Guo acquired her bachelor's degree in preventive medicine from the School of Medicine of Southeast University in 2002. After graduation in 2002, she worked in mental health prevention and health education in the Qibao Community Health Service Center of Shanghai. In 2013, she took up the post of public health doctor at Shanghai Pudong New District Center for Disease Control and Prevention. Her research interests are rehabilitation of individuals with schizophrenia in the community and psychosomatic medicine training for general practitioners. 